\title{
CARACTERÍSTICAS SÓCIO-EMOCIONAIS DO SUPERDOTADO: QUESTÕES ATUAIS
}

\author{
Eunice M. L. Soriano de Alencar
}

\begin{abstract}
RESUMO. É o objetivo principal do artigo focalizar características sócio-emocionais do superdotado. Nota-se que essa dimensão, apesar de sua importância, vem recebendo menor atenção dos estudiosos da área do que habilidades cognitivas e necessidades educacionais do superdotado. Entre outros aspectos, a assincronia entre distintas dimensões do desenvolvimento, o perfeccionismo, a hipersensibilidade, o subrendimento são discutidos, apresentando-se fatores a eles associados bem como estudos nos quais distintas características sócio-emocionais do superdotado foram investigadas. O artigo finaliza apontando a necessidade de orientação ao superdotado e a sua família e de um sistema educacional que reconheça e atenda as necessidades desse aluno nas distintas esferas - intelectual, social e emocional.
\end{abstract}

Palavras-chave: superdotados, características sócio-emocionais, ajustamento.

\section{SOCIO-EMOTIONAL CHARACTERISTICS OF THE GIFTED: PRESENT QUESTIONS}

\begin{abstract}
The main purpose of the article is to describe socio-emotional characteristics of the gifted. It is noted that, in spite of its importance, this dimension has received less attention than the cognitive abilities and educational needs of gifted children in the literature of the field. Among other aspects, the asynchronous development, perfectionism, high levels of sensibility, underachievement are discussed, describing factors related to these aspects, as well as studies focusing several socio-emotional characteristics of the gifted. The article finalizes highlighting the need of counseling to the gifted and their families and an educational system that recognizes and attends the gifted needs in the several spheres - intellectual, social and emotional.
\end{abstract}

Key words: Gifted, socio-emotional characteristics, adjustment.

\section{CARACTERÍSTICAS SOCIO-EMOCIONALES DEL SUPERDOTADO: CUESTIONES ACTUALES}

\begin{abstract}
RESUMEN. Este artículo tiene como objetivo principal abordar características socio-emocionales del superdotado. Se nota que esta dimensión, a pesar de su importancia, viene recibiendo menor atención que las habilidades cognitivas y necesidades educativas del superdotado. Se discuten, entre otros aspectos, la asincronía entre distintas dimensiones del desarrollo, el perfeccionismo, la hipersensibilidad, el subrendimiento y se presentan los factores asociados a ellos, así como estudios respecto a distintas características socio-emocionales del superdotado. El artículo se finaliza resaltando la necesidad de orientación al superdotado y a su familia y de un sistema educativo que reconozca y atienda a las necesidades del superdotado en sus distintas esferas - intelectual, social y emocional.
\end{abstract}

Palabras-clave: superdotados, características socio-emocionales, ajustamiento.

Quando se examinam os objetivos de programas para o superdotado, observa-se que, embora o desenvolvimento de habilidades cognitivas seja o aspecto mais freqüentemente enfatizado, outros objetivos relativos à dimensão sócio-emocional também se sobressaem, como, por exemplo, favorecer o ajustamento pessoal e emocional do superdotado, promover o seu desenvolvimento social e fortalecer um autoconceito positivo (Alencar, 1986; Alencar \& Fleith, 2001; Arn \& Frierson, 1971, Tannenbaum, 1983). Nota-se, entretanto, que o foco central das propostas educacionais tem sido direcionado para a área cognitiva (Alencar \& Fleith, 2001; Colangelo \& Assouline, 2000; Passow, Mönks \& Heller, 1993). Uma atenção significativamente menor tem sido dirigida ao desenvolvimento afetivo, como

* Doutora. Professora do Programa de Pós-graduação em Educação e em Psicologia da Universidade Católica de Brasília. 
sentimentos, valores, motivação, atitudes e autoconceito. E ainda que as necessidades de aconselhamento, embora reconhecidas há longa data, apenas recentemente passaram a ser enfatizadas.

Ademais, uma análise da literatura na área da superdotação indica que a dimensão sócio-emocional, apesar de sua importância, vem recebendo menor atenção do que as características cognitivas e necessidades educacionais do superdotado. Observa-se que o número de publicações a respeito dessa dimensão, embora crescente, é relativamente menor comparativamente a outros tópicos, como identificação de superdotados e modalidades de programas que visem atender às necessidades educativas desse grupo. Um exame dos anais de distintas conferências do Conselho Mundial para o Superdotado e Talentoso apontou, por exemplo, que um percentual muito reduzido dos resumos incluídos focalizaram questões relativas à auto-estima, subrendimento, problemas emocionais, como perfeccionismo e isolamento, educação afetiva, desenvolvimento assincrônico, entre outros tópicos relativos ou interligados à dimensão sócio-emocional. $\mathrm{Na} 13^{\mathrm{a}}$ Conferência desse Conselho, realizada em Istambul em 1999, apenas 6\% dos 127 trabalhos apresentados referiam-se a aspectos sócio-emocionais da superdotação. Por outro lado, na última conferência desse Conselho, realizada em 2005, em Nova Orleans, Estados Unidos, observou-se um volume e diversidade maior de tópicos referentes à dimensão sócioemocional nas apresentações realizadas, embora o porcentual de trabalhos, com foco central nessa dimensão, fosse ainda relativamente baixo (pouco mais de $10 \%$ dos 301 resumos incluídos nos anais). Há um reconhecimento de que, apesar dos avanços das pesquisas na área, há muitas questões em descoberto, visões díspares a respeito do ajustamento do superdotado, posições divergentes e contraditórias fundamentadas em pesquisas diversas e um conhecimento incompleto a respeito de estratégias efetivamente eficientes para minorar dificuldades no domínio sócio-emocional. Observa-se também uma predominância de estudos de caso e pesquisa qualitativa, de natureza clínica, com amostras reduzidas, especialmente em investigações relativas ao subrendimento, que é uma das questões que mais vêm interessando e intrigando educadores e estudiosos da área.

É o objetivo central do presente texto focalizar algumas dimensões do ajustamento e desenvolvimento sócio-emocional do superdotado. É necessário ressaltar, entretanto, que o foco será o superdotado que se destaca na área intelectual e/ou acadêmica, o qual vem sendo alvo de maior número de estudos. Sabe-se que predomina nos dias atuais a idéia de que a superdotação englobaria uma diversidade de facetas, sendo considerados superdotados não apenas aqueles indivíduos que se sobressaem em testes tradicionais de inteligência ou na área acadêmica, mas também os que apresentam um desempenho elevado na área artística ou psicomotora, além de capacidade de liderança. Ademais, novas teorias a respeito da inteligência surgiram, como a teoria de Howard Gardner (1983, 1993) sobre inteligências múltiplas, ampliando e ressaltando um número maior de expressões de competência intelectual. Nota-se que algumas das inteligências propostas por Gardner, como a intrapessoal e a interpessoal, eram pouco discutidas pelos estudiosos da superdotação e, até anos recentes, possíveis dificuldades sociais e emocionais de crianças e jovens que se sobressaiam em algumas das inteligências propostas por esse teórico não eram objeto de investigação (Webb, 1993). Constata-se ainda uma pluralidade de concepções a respeito de quem seriam os alunos superdotados. Isto tem um impacto direto nos instrumentos e estratégias utilizadas no processo de identificação daqueles encaminhados para programas especiais. Robinson (2002) observou, por exemplo, que, nos Estados Unidos, as definições adotadas pelas escolas variam amplamente. Consequientemente, alunos que seriam selecionados para um programa não o são para outros. Este é mais um fator que contribui para resultados díspares de pesquisas a respeito de determinadas facetas da superdotação, uma vez que é freqüente serem utilizadas amostras reduzidas e oriundas, muitas vezes, de uma única escola ou programa.

\section{PROBLEMAS EMOCIONAIS E DE AJUSTAMENTO}

Quando se examinam as publicações a respeito do ajustamento sócio-emocional do superdotado, observam-se resultados discrepantes entre as pesquisas e controvérsia a respeito da extensão em que crianças e jovens intelectualmente superdotados teriam maior predisposição para apresentar problemas sociais e emocionais. Uma análise feita, por Webb (1993), indicou, por exemplo, que enquanto há autores que defendem a idéia de que os alunos superdotados apresentam uma predisposição a dificuldades sócioemocionais, outros apontam a direção contrária, ressaltando a inexistência de evidência de maior grau de dificuldades sócio-emocionais. Em um estudo realizado, por exemplo, por Lehman e Erdwins (2004), com uma amostra de 16 crianças superdotadas, 
foi constatado que essas crianças apresentaram habilidades sociais que as ajudavam em suas relações interpessoais, sentimentos mais positivos a respeito de si mesmas, além de maior maturidade em suas interações com os pares. Também Baker (2004) observou que, embora muitos educadores acreditem que estudantes superdotados tenham maior predisposição à depressão e idéias suicidas, não há evidência empírica que substancie tal posição.

Para Gross (2002), a maior parte dos estudos realizados a respeito do ajustamento sócio-emocional tem utilizado amostras de alunos que não se caracterizam por uma inteligência excepcionalmente elevada, por exemplo, um QI acima de 160. São os alunos excepcionalmente inteligentes aqueles que enfrentam maior número de situações que poderão ter um impacto negativo no seu desenvolvimento sócioemocional. Isto está em consonância com as observações de Alencar (2001; Alencar \& Virgolim, 1999) segundo a qual, dependendo do grau da inteligência, aliado a outras variáveis, como classe social, gênero, possibilidades de contato com colegas de nível similar de inteligência e oportunidades de um atendimento educacional especial, dificuldades de ajustamento poderão ou não ser observadas.

É notório que Terman (1965), que realizou um dos estudos mais conhecidos na área, com uma amostra de 1528 indivíduos superdotados, identificados através de testes de QI durante a sua infância e acompanhados ao longo de várias décadas, chamou a atenção para o fato de que, contrário à idéia prevalente no início do século XX, os superdotados apresentavam, além de uma inteligência superior, um desenvolvimento físico mais acelerado, eram mais ajustados socialmente e mais estáveis do ponto de vista psicológico. Entretanto, a sua amostra tinha um QI médio de 150, sendo todos os participantes da pesquisa de status sócio-econômico médio, e muitos deles também apontados pelos seus professores para compor a referida amostra. $\mathrm{O}$ próprio Terman reconheceu, entretanto, que as crianças que tinham um QI extremamente elevado (acima de 170) apresentavam dificuldades de ajustamento social, sendo considerados pelos seus professores como solitários e pouco hábeis no seu relacionamento com pares (Burks, Jensen \& Terman, 1930, em Gross, 2002). Outras pesquisas, como o estudo clássico de Hollingworth (1942) e de Gross (1993, 2002), com amostras de alunos com QI extremamente elevado (igual ou superior a 180), têm apontado problemas de ajustamento e dificuldades emocionais, que são menos freqüentes entre superdotados cujo QI esteja na faixa de 130 a 170. Hollingworth, que realizou há mais tempo um estudo com alunos que apresentavam um QI muito elevado (pelo menos de 180) constatou, por exemplo, três problemas principais na amostra por ela estudada. O primeiro dizia respeito a ausência de hábitos adequados de trabalho no ambiente escolar. De modo geral, estes alunos não se empenhavam na escola e passavam considerável tempo alheios e sonhando acordado. Para eles, a frequiência à escola era tida como perda de tempo, dada a distância entre as demandas da escola e as suas competências pessoais. Um segundo problema observado foi a dificuldade por parte dos mesmos em suas relações sociais. Embora se empenhassem para ter amigos, o seu grupo de idade não compartilhava de seus interesses, o que dificultava a sua interação, levando-os a se isolar. Um terceiro problema observado foi uma certa vulnerabilidade emocional, explicada por Hollingworth em função da capacidade destes alunos de entender e se envolver com questões éticas e filosóficas, antes de estarem emocionalmente maduros para lidar com tais questões (Hollingworth, 1942).

Hollingworth observou, entretanto, que mudanças radicais ocorriam no comportamento de alunos excepcionalmente inteligentes, quando tinham oportunidade de passar a interagir com pares similares em inteligência. Alunos que, por exemplo, eram retraídos, socialmente distantes, pouco participativos nas atividades escolares, uma vez em contato com grupos de idade mental similar, passavam a atuar de uma forma adequada, dando contribuições significativas nas atividades de grupo e se comportando como um indivíduo socializado e feliz (em O'Shea, 1965).

Também Gross $(1993,2002)$ constatou, em estudo realizado na Austrália, que a grande maioria dos alunos excepcionalmente inteligentes que não tinham tido oportunidade de serem acelerados, apresentavam níveis mais baixos de motivação e auto-estima e mais frequientemente eram rejeitados por seus colegas de escola. Com relação aos alunos excepcionalmente inteligentes, a autora (1993) ressalta:

Estudantes excepcionalmente inteligentes diferem de forma radical de outros moderadamente superdotados não apenas em seu desenvolvimento cognitivo, mas em seu crescimento afetivo, desenvolvimento moral, interesses recreativos, interesses de leitura, escolha de amizades, atitudes e valores, além da maneira como vêem o mundo... Esses estudantes correm sério risco de isolamento social e rejeição pelos pares, a menos que o sistema educacional proporcione a eles um grupo de colegas baseado não em idade 
cronológica, mas em habilidades, interesses comuns e nível desenvolvimental (p. 497).

Observações similares às de Hollingworth e Gross quanto ao isolamento de alunos com inteligência extremamente elevada foram feitas por nós em um estudo de caso com um aluno de inteligência excepcionalmente elevada, cujo QI era de 172 e que obteve no Scholastic Aptitude Test 710 pontos na parte de matemática quando tinha 11 anos e 10 meses, resultado este correspondente ao percentil 96 de amostras universitárias norte-americanas (Alencar \& Fleith, 1996). O aluno que, na época em que os dados a seu respeito foram coletados, tinha 12 anos, era, segundo seus professores, reservado, quieto e preferia trabalhar isoladamente. Tinha poucos amigos, o que era explicado por seus professores em função da diferença de idade entre ele e seus colegas de classe.

Muitos dos problemas que se observam entre alunos que se destacam por um potencial superior têm a ver com o desestímulo e frustração sentida por eles diante de um programa acadêmico que prima pela repetição e monotonia e por um clima psicológico em sala de aula pouco favorável à expressão do potencial superior. A escola não atende, de forma adequada, os alunos que apresentam habilidades intelectuais superiores, o que ajuda a explicar a apatia e ressentimento apresentados freqüentemente por estes alunos.

Uma análise do que ocorre com a maior parte dos alunos que apresentam habilidades intelectuais significativamente superiores na escola foi feita por Terrassier (1981), que chama de "efeito pigmalião negativo" o que acontece no ambiente acadêmico. Nota-se que "efeito pigmalião" foi um termo introduzido por Rosenthal e Jacobson, em 1968, para chamar a atenção para resultados observados por estes autores em estudos nos quais professores, que foram informados a respeito da competência acadêmica e intelectual superiores de alguns alunos escolhidos ao acaso, passaram a agir de forma diferenciada com relação a estes alunos, levando-os efetivamente a apresentar um desempenho que correspondia à avaliação que os seus professores haviam recebido a seu respeito. No caso do aluno que apresenta um potencial superior, aspecto este, porém, desconhecido pelo professor, um fenômeno inverso pode ocorrer. Como o professor não tem idéia do potencial real de alunos que apresentam habilidades superiores ou uma precocidade intelectual, ele passa a esperar do mesmo um desempenho na faixa da média, encorajando-o a apresentar um desempenho muito aquém de suas reais capacidades. Isto, segundo Terrassier, dificultaria ao superdotado expressar o seu potencial. Acresce-se ainda a influência do grupo de colegas da mesma série e/ou idade, que também têm expectativas sobre os seus colegas mais brilhantes, gerando pressão que podem levá-los a um desempenho muito aquém de suas possibilidades intelectuais, a par de várias dificuldades de natureza emocional.

O descompasso entre o desenvolvimento intelectual e o emocional é também fonte de tensões e origem de desajustamento e quanto maior o grau de assincronia, maior a probabilidade de problemas de ajustamento de ordem social e emocional (Silverman, 2002). Landau (1990) lembra este descompasso e a necessidade de que o superdotado seja compreendido com relação a este aspecto, destacando:

Em algumas situações, vejo a criança superdotada como o atleta que corre longas distâncias. À frente de outras crianças, no entanto, apenas intelectualmente ou em campos específicos. Se não nos mantivermos a seu lado, para ensiná-la a vencer o intervalo entre o desenvolvimento emocional cronológico e o intelectual, mais adiantado, ela se sentirá dividida, solitária e usará toda a sua energia para tentar equilibrar esses extremos de sua personalidade (p. XXIV).

Esta assincronia entre distintas dimensões do desenvolvimento tem sido sistematicamente apontada por distintos autores, como Coleman e Cross (2000), Moon, (2004), Peterson (2003) e Silverman (1993, 2002). Foi talvez Hollingworth a primeira pesquisadora a chamar a atenção para este aspecto, ao destacar que ter a inteligência de um adulto e as emoções de uma criança em um corpo de criança envolve certas dificuldades (Silverman, 1993). É comum, por exemplo a família esperar comportamentos típicos de uma criança mais velha por conta das habilidades intelectuais mais avançadas, o que, entretanto, não ocorre, gerando insatisfação e irritação de ambas as partes. Estas dificuldades são penosas de se lidar, tanto pela criança quanto pela sua família. Esta última se espanta com as reações da criança superdotada, uma vez que espera dela um comportamento com base unicamente na sua capacidade intelectual mais avançada.

O desenvolvimento heterogêneo de diferentes áreas foi também analisado por Terrassier (1979), que propôs o termo "síndrome da dissincronia" para caracterizar a disparidade entre diferentes facetas do desenvolvimento do superdotado. Este autor contrasta dois tipos de dissincronia. Uma, de ordem interna, que ocorre no interior da própria criança e outro entre a criança e seu ambiente, incluindo tanto a escola como a família. 
A dissincronia de ordem interna diz respeito aos diferentes ritmos de desenvolvimento que podem ser observados entre as áreas intelectual, psicomotora, lingüística e afetivo-emocional. Terrassier lembra, por exemplo, que é muito freqüente o superdotado aprender a ler facilmente em uma idade precoce, encontrando, porém, dificuldades na área da escrita. A discrepância entre o nível mental e os níveis psicomotor e gráfico, estes últimos muito mais de acordo com a idade cronológica do que a idade mental, é mais freqüentemente observada entre meninos, fazendo com que muitos se sintam frustrados diante de sua inabilidade de usar as mãos na mesma velocidade de seu ritmo mental, levando-os a reagir inicialmente com tentativas de controle, que mal-sucedidas geram ansiedade, o que, por sua vez, leva a uma escrita ainda mais irregular acompanhada de sentimentos de desconforto e frustração.

Outra disparidade comum é o aluno ter uma habilidade matemática excepcional, sendo, porém, medíocre em ortografia e escrita. Como a escola tende a esperar que o aluno progrida de uma maneira homogênea em diferentes disciplinas, isto pode gerar dificuldades para o aluno, sobretudo de natureza emocional.

Também a discrepância entre o desenvolvimento intelectual e a maturidade afetiva é analisada por Terrassier (1979). Este autor considera que o superdotado pode ser, por exemplo, dominado pelo medo e ansiedade oriundos de reflexões que faz a respeito de problemas enfrentados pela humanidade ou a partir de leituras sobre temas geradores de ansiedade, com as quais ele não sabe lidar.

Apesar de ser o desenvolvimento assincrônico bastante discutido pelos especialistas da área, segundo Silverman (2002), o mesmo não foi ainda estudado de forma sistemática, sendo a vasta maioria da literatura, referente a esta faceta do desenvolvimento, baseada em observações clínicas de indivíduos superdotados, com base na análise de sua experiência fenomenológica.

O perfeccionismo, excesso de autocrítica, sensibilidade exacerbada, entre outras características associadas à dimensão emocional, têm sido também apontados com possíveis fontes de stress para crianças e jovens com altas habilidades intelectuais. $\mathrm{O}$ perfeccionismo diz respeito a "uma combinação de pensamentos e comportamentos geralmente associados a altos padrões ou expectativas com relação ao próprio desempenho" (Schuler, 2002, p. 71), variando em uma gradação que vai do normal ou saudável ao neurótico ou não-saudável. Estudos realizados por Schuler (2000, 2002; Schuler \& cols., 2003) e Moreira (2005) constataram que muitos superdotados apresentam o perfeccionismo que se caracteriza como saudável, constituindo-se em uma influência positiva para a sua realização pessoal. Estes estabelecem altos padrões de desempenho, dedicam-se com afinco e comprometimento na realização das tarefas referentes às metas que almejam alcançar, têm expectativas mais realistas com relação a si mesmos, apresentam sentimentos de prazer ao perceber o resultado positivo de seus esforços, reconhecendo e aceitando tanto os seus pontos fortes quanto as suas limitações. Por outro lado, os perfeccionistas neuróticos são incapazes de se sentirem satisfeitos com o seu próprio desempenho, uma vez que consideram que o que fazem nunca atinge o nível que gostariam. É comum refazerem o mesmo trabalho muitas vezes, investindo uma grande quantidade de tempo e energia para alcançar o nível de qualidade que desejam nas tarefas realizadas. São ainda dominados pelo medo do fracasso, excessivamente autocríticos e altamente sensíveis às críticas externas, além de considerarem os próprios erros, não como uma oportunidade para aprender, mas antes como algo humilhante, a ser evitado a todo custo. É freqüente apresentarem-se como ansiosos, preocupados e inseguros a respeito de seu desempenho.

No Brasil, um estudo realizado por Moreira (2005), com uma amostra de 51 estudantes superdotados, que freqüentavam o programa para alunos com altas habilidades da Secretaria de Educação do Distrito Federal, indicou que 34 (66,67\%) se classificaram como perfeccionistas saudáveis e 10 $(19,61 \%)$ como perfeccionistas não-saudáveis. Um percentual similar de perfeccionistas foi observado em estudo realizado por Schuler (2000), com uma amostra de 112 alunos superdotados, dos quais 98 se identificaram como perfeccionistas. Entretanto, deste total, $65(58,03 \%)$ da amostra total foram classificados como saudáveis e $33(29,46 \%)$ como não-saudáveis. Tais resultados chamam a atenção para um número significativo de alunos superdotados que necessitam de assistência, no sentido de que possam compreender e lidar melhor com a psicodinâmica de sua conduta, buscando reverter a dimensão disfuncional e destrutiva do perfeccionismo que apresentam.

A sensibilidade e intensidade emocionais observadas entre superdotados têm sido examinadas especialmente à luz da teoria de Dabrowski do desenvolvimento emocional (O'Connor, 2002; Piechowski, 1991). Esse psiquiatra polonês, que estudou a saúde mental de superdotados nas áreas intelectuais e artísticas, propôs a teoria da 
desintegração positiva, identificando altos níveis de excitabilidade, que se manifestariam em distintas dimensões da vida psíquica (psicomotora, sensorial, intelectual, emocional e imaginativa), considerados por ele como catalisadores para um desenvolvimento emocional mais avançado. Distintas escalas foram construídas para avaliar os altos níveis de excitabilidade. Estratégias foram também elaboradas, com base nessa teoria, para ajudar o superdotado a lidar e apreciar essa característica de seu desenvolvimento emocional, que tradicionalmente é pouco compreendida por pais e professores.

Um dos tópicos que vêm sendo objeto de intensa discussão por parte dos estudiosos da superdotação, em especial daqueles interessados nas necessidades sócioemocionais do superdotado, é o fenômeno do subrendimento. Este tem sido, por exemplo, o problema mais focalizado no programa de Aconselhamento Familiar do Centro Internacional Connie Belin \& Jacqueline N. Blank para a Educação do Superdotado e Desenvolvimento do Talento da Universidade de Iowa, nos Estados Unidos (Colangelo \& Assouline, 2000). Embora não haja pleno acordo quanto à sua definição, poder-se-ia ressaltar que o que caracteriza o subrendimento é uma elevada discrepância entre o desempenho acadêmico e indicadores de um alto potencial intelectual, como, por exemplo, resultados em testes de inteligência (ButlerPor, 1993; Colangelo \& Assouline, 2000; Passow, Mönks \& Heller, 1993).

Entre os fatores que contribuem ou estão associados ao subrendimento, poder-se-iam apontar tanto características individuais quanto elementos da família, escola e sociedade. Os distintos fatores relacionam entre si de maneira interdependente e complexa. Entre as características individuais, ressaltam-se, entre outras, uma baixa auto-estima, depressão, ansiedade, perfeccionismo, irritabilidade, não-conformismo, hostilidade e comportamento agressivo, lócus de controle externo, impulsividade e déficit de atenção (Alencar, 2001; Butler-Por, 1993; Colangelo \& Assouline, 2000; Peterson, 2003; Reis \& McCoach, 2002, Rimm, 1991). Baixas expectativas parentais, atitudes inconsistentes dos pais a respeito das realizações do filho, excessiva pressão dos pais em relação ao desempenho acadêmico, conflitos familiares e clima predominante no lar, refletindo em menor grau de apoio, segurança e compreensão das necessidades da criança ou jovem são características da família que podem também contribuir para o subrendimento do aluno. Um ambiente acadêmico pouco estimulante, métodos de ensino centrados no professor, excesso de exercícios repetitivos, baixas expectativas do professor com relação ao desempenho do aluno, pressão ao conformismo, procedimentos docentes rígidos, com estandardização do conteúdo, aliado ao pressuposto de que todos os alunos devem aprender no mesmo ritmo e de mesma forma, além de uma cultura antiintelectualista são elementos que também ajudam a explicar o fenômeno do subrendimento. Ademais a necessidade de ser aceito pelos pares faz com que muitos alunos com altas habilidades, que se encontram na escola regular, optem por disfarçar o seu potencial intelectual superior, apresentando um rendimento acadêmico muito aquém de suas possibilidades.

\section{A NECESSIDADE DE ORIENTAÇÃO E ACONSELHAMENTO AO SUPERDOTADO E À FAMÍLIA}

Com o objetivo de ajudar o superdotado que apresenta problemas e dificuldades de ordem psicológica, vários centros e serviços de aconselhamento foram criados, especialmente nos Estados Unidos, país que mais tem investido na educação daqueles alunos que se destacam por um potencial superior. Um destes Serviços, denominado Programa de Apoio às Necessidades Emocionais do Superdotado foi, por exemplo, fundado há mais de 20 anos na Wright State University, após o suicídio de um adolescente intelectualmente brilhante. Alguns destes centros, como o da Universidade de Iowa, vem atuando não apenas no aconselhamento psicológico, mas também na orientação vocacional e aconselhamento familiar (Colangelo, 1991). Entre os problemas, que têm sido apontados entre superdotados que necessitam desses serviços, salientam-se o perfeccionismo e medo do fracasso, ambivalência a respeito de si mesmo, baixa auto-estima, subrendimento, desvio das normas impostas pela família e pelo grupo de mesma idade, além do isolamento social.

Por outro lado, um dos problemas críticos enfrentados por muitos superdotados na escolha profissional diz respeito às pressões para que sigam determinadas carreiras mais valorizadas socialmente e que são tidas como mais adequadas àqueles alunos que se destacam por suas habilidades superiores. Segundo Colangelo (1991), estas pressões podem dificultar a este aluno "seguir o seu coração" na escolha profissional, diante da oposição encontrada na própria família, que não deseja ver o filho desperdiçar o talento em áreas tidas como de menor prestígio.

Outras dificuldades podem ser vividas também pelo superdotado no meio da família em função de 
pais superambiciosos, que pressionam permanentemente o filho para que ele se destaque cada vez mais, vendo neste um caminho para a sua própria realização e satisfação de desejos frustrados de sucesso e projeção.

Também a família do superdotado, muitas vezes, necessita de aconselhamento. Algumas têm dificuldade em lidar com a discrepância entre o desenvolvimento intelectual e emocional do superdotado, sendo esta, inclusive, a maior dificuldade apontada pelos pais nas suas relações com filhos que se destacam por uma inteligência superior, conforme observado por Landau (1990). Muitos pais sentem-se perdidos sobre a melhor maneira de lidar e orientar o seu filho com altas habilidades. Esta dificuldade é sentida com freqüência em nosso meio, dado o reduzido número de programas de ordem acadêmica voltados para o superdotado, que venham a atender às suas necessidades de aprendizagem e possibilitar-lhes o contato com colegas que também se sobressaem por um potencial superior. O problema se agrava diante dos preconceitos e idéias errôneas sobre o superdotado, comuns em nosso meio, dificultando a sua adaptação na escola, podendo levar a um enorme desperdício de potencial e de talento, conforme temos apontado em várias publicações (Alencar, 1986, 1994, 2001; Alencar \& Fleith, 2001).

Muitas das dificuldades que o superdotado enfrenta em nosso meio se devem também ao rótulo. Como destacamos anteriormente (Alencar, 1986, 1994, 2001; Alencar \& Fleith, 2001), o problema do rótulo é sério, especialmente devido ao prefixo "super", que sugere a idéia de um desempenho invariavelmente elevado, e o fenômeno da superdotação como algo muito raro, e, portanto, com poucos alunos podendo serem classificados como tal. Observa-se ainda uma ênfase no genótipo, ou seja, a idéia da superdotação como um dote que o indivíduo já traria ao nascimento, e que se realizaria, independentemente das condições ambientais.

A fim de prevenir ou minorar o desajuste emocional de crianças e jovens superdotados, seria desejável que pais e professores fossem orientados a respeito das características pessoais, desenvolvimento cognitivo, necessidades sociais e emocionais e habilidades desses indivíduos. Infelizmente isto vem ocorrendo de forma muitíssimo limitada em grande número de países, permanecendo a família desamparada, além de ser a escola pouco equipada para propiciar experiências educacionais de qualidade aos superdotados. Ajudá-los a desenvolver seu potencial, a se sentirem compreendidos e aceitos é tarefa que todos nós, estudiosos da superdotação, necessitamos abraçar, empenhando-nos na construção de um sistema educativo que reconheça e atenda as necessidades do superdotado em suas distintas esferas - intelectual, social e emocional.

Espera-se que o presente texto contribua para chamar a atenção, do público em geral e dos psicólogos e estudantes de Psicologia em especial, para as características emocionais do superdotado, aspecto este pouco discutido na grande maioria dos cursos de Psicologia. Este é um tema de grande relevância, especialmente pela necessidade de medidas de apoio àqueles alunos que se destacam por um potencial superior, de tal forma que possam lidar melhor com a sua dimensão sócio-emocional.

\section{REFERÊNCIAS}

Alencar, E. M. L. S. (1986). Psicologia e educação do superdotado. São Paulo: EPU.

Alencar, E. M. L. S. (1994). Perspectivas e desafios da educação do superdotado. Em E. M. L. S. Alencar (Org.), Tendências e desafios da educação especial (pp. 104-124). Brasília: Secretaria de Educação Especial.

Alencar, E. M. L. S. (2001). Criatividade e educação de superdotados. Petrópolis: Vozes.

Alencar, E. M. L. S. \& Fleith, D. S. (1996). Lim: características e desenvolvimento de uma criança com uma inteligência matemática excepcional. Cadernos de Pesquisa NEP, 2, 1-11.

Alencar, E. M. L. S. \& Fleith, D. S. (2001). Superdotados: determinantes, educação e ajustamento. São Paulo: EPU.

Alencar, E. M. L. S. \& Virgolim, A. M. R. (1999). Dificuldades sociais e emocionais do superdotado. Em F. P. N. Sobrinho \& A. C. B. Cunha (Orgs.), Dos problemas disciplinares aos desvios de conduta: práticas e reflexões (pp. 89-114). Rio de Janeiro: Dunya.

Arn, W. \& Frierson, E. (1971). An analysis of programs for the gifted. In J. C. Gowan \& E. P. Torrance (Eds.), Educating the ablest. Itasca: Peacock.

Baker, J. A. (2004). Depression and suicidal ideation among academically gifted adolescents. In S. M. Moon (Ed.), Social/emotional issues, underachiemenvt and counseling of gifted and talented students (pp. 21-30). Thousand Oaks: Corwin.

Butler-Por, N. (1993). Underachieving gifted students. In K. A. Heller, F. J. Mönks \& A. H. Passow (Eds.), International handbook of research and development of giftedness and talent (pp. 649-668). Oxford: Pergamon.

Colangelo, N. (1991). Counseling gifted students. In N. Colangelo \& G. A. Davis (Eds.), Handbook of gifted education (pp. 273282). Boston: Allyn and Bacon.

Colangelo, N. \& Assouline, S. G. (2000, $2^{\text {nd }}$ Ed.). Counseling gifted students. In K. A. Heller, F. J. Mönks, R. J. Sternberg \& R. F. Subotnik (Eds.), International handbook of research and development of giftedness and talent (pp. 595-608). Oxford: Elsevier. 
Coleman, L. J. \& Cross, T. L. (2000, $2^{\text {nd }}$ Ed.). Social-emotional development and the personal experience of giftedness. In K. A. Heller, F. J. Mönks, R. J. Sternberg \& R. F. Subotnik (Eds.), International handbook of research and development of giftedness and talent (pp. 203-212). Oxford: Elsevier.

Gardner, H. (1983). Frames of mind: The theory of multiple intelligences. New York: Basic Books.

Gardner, H. (1993). Multiple intelligences. The theory in practice. New York: Basic Books.

Gross, M. U. M. (1993). Nurturing the talents of exceptionally gifted individuals. In K. A. Heller, F. J. Mönks \& A. H. Passow (Eds.), International handbook of research and development of giftedness and talent (pp. 473-490). Oxford: Pergamon.

Gross, M. U. M. (2002). Social and emotional issues for exceptionally intellectually gifted students. In M. Neihart, S. M. Reis, N. M. Robinson \& S. M. Moon (Eds.), The social and emotional development of gifted children (pp. 19-30). Waco: Pufrock.

Hollingworth, L. (1942). Children above 180 IQ: Origin and development. New York: World Books.

Landau, E. (1990). A coragem de ser superdotado. São Paulo: CERED.

Lehman, E. B. \& Erdwins, C. J. (2004). The social and emotional adjustment of young intellectually gifted children. In S. M. Moon (Ed.), Social/emotional issues, underachievement and counseling of gifted and talented students (pp. 1-8). Thousand Oaks: Corwin.

Moon, S. M. (Ed.) (2004). Social/emotional issues, underachievement, and counseling of gifted and talented students. Thousand Oaks: Corwin.

Moreira, G. E. (2005). Perfeccionismo em adolescentes superdotados atendidos em um programa para alunos com altas habilidades/talentosos. Dissertação de Mestrado NãoPublicada, Programa de Mestrado em Educação da Universidade Católica de Brasília, Brasília.

O'Connor, K. J. (2002). The application of Dabrowski's theory to the gifted. In M. Neihart, S. M. Reis, N. M. Robinson \& S. M. Moon (Eds.), The social and emotional development of gifted children (pp. 51-60). Waco: Pufrock.

O'Shea, H. E. (1965). Friendship and the intellectually gifted child. In W. B. Barbe (Ed.), Psychology and education of the gifted: Selected readings (pp. 282-291). New York: AppletonCentury-Crofts.

Passow, A. H., Mönks, F. J. \& Heller, K. A. (1993). Research and education of the gifted in the year 2000 and beyond. In K. A. Heller, F. J. Mönks \& A. H. Passow (Eds.), International handbook of research and development of giftedness and talent (pp. 883-903). Oxford: Pergamon.

Peterson, J. S. (2003). Underachievers: Students who don't perform. In J. F. Smutny (Ed.), Underserved gifted populations (307-332). Creskill: Hampton.

Piechowski, M. M. (1991). Emotional development and emotional giftedness. In N. Colangelo \& G. A. Davis (Eds.), Handbook of gifted education (pp. 285-307). Boston: Allyn \& Bacon.
Reis, S. M. \& Coach, D. B. (2002). Underachievement in gifted students. In M. Neihart, S. M. Reis, N. M. Robinson \& S. M. Moon (Eds.), The social and emotional development of gifted children (pp. 81-92). Waco: Pufrock.

Rimm, S.B. (1991). Underachievement and superachievement: Flip slides of the same psychological coin. In N. Colangelo \& G. A. Davis (Eds.), Handbook of gifted education (pp. 328343). Boston: Allyn \& Bacon.

Robinson, N. M. (2002). Individual differences in gifted students' attributions for academic performances. In M. Neihart, S. M. Reis, N. M. Robinson \& S. M. Moon (Eds.), The social and emotional development of gifted children (pp. 31-40). Waco: Pufrock.

Schuler, P. (2000). Perfeccionsim and gifed adolescents. The Journal of Secondary Gifted Education, 11, 183-196.

Schuler, P. (2002). Perfectionism in gifted children and adolescents. In M. Neihart, S. M. Reis, N. M. Robinson \& S. M. Moon (Eds.), The social and emotional development of gifted children (pp. 71-80). Waco: Pufrock.

Schuler, P., Ferbezer, I., O'Leary, N., Popova, L. V., Delou, C. M. C. \& Limont, W. (2003). Perfeccionism: International case studies. Gifted and Talented International, 18, 67-75.

Silverman, L. K. (1993). Counseling needs and programs for the gifted. In K. A. Heller, F. J. Mönks \& A. H. Passow (Eds.), International handbook of research and development of giftedness and talent (pp. 631-647). Oxford: Pergamon.

Silverman, L. K. (2002). Asynchronous development. In M. Neihart, S. M. Reis, N. M. Robinson \& S. M. Moon (Eds.), The social and emotional development of gifted children (pp. 31-40). Waco: Pufrock.

Tannenbaum, A. J. (1993). Gifted children. Psychological and educational perspectives. New York: Macmillan.

Terman, L. M. (1965). The discovery and encouragement of exceptional talent. In W. B. Barbe (Ed.), Psychology and education of the gifted: Selected readings (pp. 8-28). New York: Appleton-Century-Crofts.

Terrassier, J. C. (1979). Gifted children and psychopathology. The syndrome of dyssinchrony. In J. J. Gallagher (Ed.), Gifted children: Reaching their potential (pp. 434-440). Jerusalem: Kollek \& Son.

Terrassier, J. C. (1981). The negative pigmalian effect. In A. H. Kramer (Ed.), Gifted children: Challenging their potential: New perspectives and alternatives (pp. 82-84). New York: Trillium.

Webb, J. T. (1993). Nurturing social-emotional development of gifted children. In K. A. Heller, F. J. Mönks \& A. H. Passow (Orgs.), International handbook of research and development of giftedness and talent (pp. 525-538). Oxford: Pergamon.

Recebido em 24/08/2006 Aceito em 29/11/2006

Endereço para correspondência: Eunice M. L. Soriano de Alencar. Programa de Mestrado em Educação, Universidade Católica de Brasília, SGAN 916 Módulo B Asa Norte, Cep 70790-160, Brasília-DF. E-mail: ealencar@pos.ucb.br 